\title{
Simultaneous Saccharification and Fermentation of Starch from Pongamia Pinnata Oilcake into Ethanol
}

\author{
Vidya Sundaram ${ }^{1}$, Saraswathy Nachimuthu ${ }^{2}$, Ramalingam Ponnusamy ${ }^{2}$ \\ ${ }^{1}$ Department of Biotechnology, Bannari Amman Institute of Technology \\ Sathymangalam, Erode, Tamil Nadu, India 638401 \\ vidyasundaram22@gmail.com \\ 2Department of Biotechnology, Kumaraguru College of Technology \\ Coimbatore, Tamil Nadu, India 641049 \\ saraswathy.n.bt@kct.ac.in; ramalingam.p.bt@kct.ac.in
}

\begin{abstract}
Simultaneous saccharification and fermentation of Pongamia pinnata oilcake to ethanol was comparatively studied using co-culture of Aspergillus niger and Saccharomyces cerevisiae as well as with the combination of Aspergillus niger and Kluyveromyces marxianus. As a prerequisite, the amount of total carbohydrate, starch and reducing sugar in the oilcake were estimated and found to be $23 \%, 7.8 \%$ and $15.8 \%$ respectively. The present investigation was carried out with inoculum concentrations varying from $2 \%$ $(\mathrm{g} / \mathrm{g})$ to $5 \%(\mathrm{~g} / \mathrm{g})$ and various substrate concentrations of $5 \mathrm{~g}$ to $20 \mathrm{~g}$. The fermentation was carried out from $24 \mathrm{~h}$ to $96 \mathrm{~h}$ and the ethanol produced was simultaneously estimated by back titration with sodium thiosulphate. The co-culture of $S$. cerevisiae and $A$. niger yielded a maximum ethanol concentration of $6.96 \mathrm{~g} / \mathrm{l}$ with $3 \%(\mathrm{~g} / \mathrm{g})$ inoculum utilizing $5 \mathrm{~g}$ oilcake at $48 \mathrm{~h}$ whereas the co-culture of $K$. marxianus and $A$. niger produced maximum ethanol concentration of $7.41 \mathrm{~g} / \mathrm{l}$ under optimum conditions of $15 \mathrm{~g}$ of substrate at $96 \mathrm{~h}$ with $3 \%$ $(\mathrm{g} / \mathrm{g})$ inoculum.
\end{abstract}

Keywords: Pongamia oilcake, ethanol, co-culture, Aspergillus niger, Saccharomyces cerevisiae, Kluyveromyces marxianus.

(C) Copyright 2016 Authors - This is an Open Access article published under the Creative Commons Attribution License terms (http://creativecommons.org/licenses/by/3.0). Unrestricted use, distribution, and reproduction in any medium are permitted, provided the original work is properly cited.

\section{Introduction}

Rise in the prices of the fossil fuels due to their rapid depletion coupled with an increased incidence of global warming caused by $\mathrm{CO}_{2}$ emissions has taken its toll on the world today [1]. It is predicted that by the year 2050, the global crude oil production will face a huge decline from 25 billion barrels to 5 billion barrels approximately. Available statistics and discovery of dried up oil wells indicate that the end of oil is near which mandates the search for new alternative fuels. Biofuels (bio-ethanol and biodiesel) have become the cynosure of all eyes in the light of energy crisis and greener environment [2].

Bioethanol contributes to $90 \%$ of the global biofuel usage. It has stirred an interest in bio-fuels due to its evolution as an alternative motor fuel. Innovations and technologies have steadily increased the efficiency of ethanol production processes [3]. The emphasis today is on the attainment of an economically feasible process which should reduce the cost of production in order to make the fuel affordable. The important parameters that could affect the overall cost of the ethanol production process are availability of substrates and its efficient utilization and reduction of by-products. The major feedstocks currently used for ethanol production are sugarcane molasses in Asia and Africa, sugarcane juice in Brazil and corn in the USA. When using these feedstocks, the raw material itself accounts for $40-70 \%$ of the total cost of production. Moreover, in the long run, these feedstocks will not support the increased demand for the fuel, ethanol. The supply of cheap raw material to achieve lower production costs and increased quantity of ethanol is thus a necessity [4]. 
Across the globe, tree-born non-edible oil seeds occurring in the wild or those cultivated sporadically have been exploited for biodiesel production. These seeds undergo a process of extraction in which $35 \%$ of them are converted into vegetable oils and the remaining $65 \%$ is rejected as de-oiled seedcake [5]. India is endowed with more than 100 species of the oilbearing seeds, out of which Pongamia pinnata has been found to be one of the most suitable species, the seeds of which can be utilized as a source of biodiesel. The seeds of $P$. pinnata have an oil content of $27-39 \%$ yielding 0.055 metric tonnes of vegetable oil and 0.145 metric tonnes of oilcake per year ${ }^{6}$. Considering the future trends of oil seeds utilization for biodiesel production in the country, there arises a need for the efficient utilization of their oilcakes. Reports have been made on the starch availability of the seeds of $P$. pinnata [6]-[9]. Thus the under-utilized, starch rich oilcake of $P$. pinnata can be strategically utilized for ethanol production.

Microbial conversion of biomass materials to ethanol through fermentation involves formation of a solution of fermentable sugars and fermentation of these sugars to ethanol. Saccharomyces cerevisiae and its related species produce more than $90 \%$ of the global ethanol [10]. But this yeast is unable to hydrolyze starch. The traditional starch-to-ethanol process involves the saccharification of starch by amylolytic enzymes followed by fermentation using S. cerevisiae. In order to overcome the additional cost of enzymes, a new technique that combines both hydrolysis and fermentation of starch, referred to as simultaneous saccharification and fermentation (SSF) was introduced which involves co-culturing of an amylase producing organism and a fermenting organism in the same vessel [11]. These organisms would synergistically utilize the substrates for food and, in the process, yield ethanol [12], [13]. The observation on Pongamia de-oiled seed cake has shown that it becomes a paste just after 4-5 hours of soaking in water. Thus, it is expected that the degradation of Pongamia de-oiled seed cake will be faster in case of submerged fermentation. Hence the oilcake can be utilized as the solid state substrate for SSF.

The purpose of the present study is to develop a single-step system for enhanced fermentation of Pongamia oilcake starch and also the optimization of the process variables to maximize ethanol yield.

\section{Materials and Methods}

\subsection{Substrate and Pretreatment}

The oilcake of Pongamia was collected from Kanmani Garden Nursery exports, Ganapathy, Coimbatore. The oilcake was air-dried, powdered and then sieved. The powdered oilcake was defatted using Soxhlet extraction apparatus for $6 \mathrm{~h}$ using n-hexane as the solvent. The defatted powder was air-dried and kept in a closed dark glass bottle and was stored at $4^{\circ} \mathrm{C}$ until utilization.

\subsection{Microorganisms and culture conditions}

S. cerevisiae MTCC 173 and K. marxianus MTCC 1388 procured from the Institute of Microbial Technology (IMTECH), Chandigarh, INDIA were maintained in yeast extract peptone dextrose (YEPD) agar medium with a composition of yeast extract $3.0 \mathrm{~g} / \mathrm{l}$, peptone $10 \mathrm{~g} / \mathrm{l}$, dextrose $20 \mathrm{~g} / \mathrm{l}$ and agar $15 \mathrm{~g} / \mathrm{l}$ at a $\mathrm{pH}$ of 5.5 and temperature $30^{\circ} \mathrm{C}$. Amylase-producing fungi $A$. niger, available in the Department culture collection was maintained in Potato Dextrose Agar (PDA) medium at a $\mathrm{pH}$ of 5.5 , and $30^{\circ} \mathrm{C}$. Fungal inocula were prepared by using agar cultures to inoculate $25 \mathrm{ml}$ of sterile PD Broth contained in $250 \mathrm{ml}$ Erlenmeyer flasks. The flasks were placed on an orbital shaker maintained at 200 rpm and $30^{\circ} \mathrm{C}$ for 5 days. $S$. cerevisiae and $K$. marxianus inoculum were prepared using YEPD broth (pH 5.5) and incubated for $48 \mathrm{~h}$ at $30^{\circ} \mathrm{C}$.

\subsection{Simultaneous Saccharification and Fermentation (SSF)}

Ethanol production by co-culture of fungi and yeast was carried out with defatted oil cakes contained in $250 \mathrm{ml}$ Erlenmeyer flasks. The medium was sterilized at 15 psi at $121^{\circ} \mathrm{C}$ for $20 \mathrm{~min}$. Moisture content of the oilcakes was maintained at a level of $70 \%$ with autoclaved distilled water. The flasks were kept in an incubator maintained at $30^{\circ} \mathrm{C}$ and $\mathrm{pH}$ was not controlled during the SSF process. The fermentation was maintained at "limited anaerobic conditions" [14], [15] with shaking at $200 \mathrm{rpm}$ for a period of $96 \mathrm{hrs}$ at different temperatures and the flasks were capped with non-absorbent cotton. The working volume of the substrate was $10 \mathrm{~g}$ and to arrive at optimum substrate concentration, the same was varied accordingly $(5,10$, 15 and $20 \mathrm{~g}$ ) for maximal ethanol production. 


\subsection{Effect of Operational parameters}

To study the effect of two combinations of cocultures, one batch of fermentation was carried out with the yeast $S$. cerevisiae and the other batch with $K$. marxianus. Both the batches were simultaneously inoculated with $A$. niger for saccharification. The effect of inoculum size on ethanol fermentation was carried out by varying the inoculum concentration of both the saccharifying organism and the fermenting organism from $2 \%$ to $5 \%(\mathrm{~g} / \mathrm{g})$ each on $10 \mathrm{~g}$ of the defatted oilcake. Effect of substrate concentration on ethanol fermentation was evaluated for 5, 10, 15 and $20 \mathrm{~g}$ of oilcake for both the batches of SSF.

All the experiments were performed in three sets of replicates and also the standard deviations were calculated. All data reported in this paper are the average of triplicates.

\subsection{Analytical procedures}

2.5.1. Analysis of Carbohydrate content of Pongamia oilcake

The total carbohydrate and starch content of the defatted oilcake were analyzed by Anthrone Method [16]. Also, the reducing sugar content of the oilcake was determined by dinitrosalicylic acid method de6scribed by Miller [17].

\subsubsection{Glucoamylase activity of $\boldsymbol{A}$. niger}

$10 \mathrm{~g}$ of the defatted oilcake was inoculated with varying inoculum concentrations of $2 \%(\mathrm{~g} / \mathrm{g})$ to $5 \%$ $(\mathrm{g} / \mathrm{g})$ of $A$. niger. Samples were withdrawn at $24 \mathrm{~h}$ interval over a period of $96 \mathrm{~h}$ and centrifuged at 10,000 rpm for $10 \mathrm{~min}$. The supernatant was used for the estimation of glucoamylase activity. Glucoamylase activity in the samples was estimated by measuring the amount of glucose released from soluble starch. The assay mixture contained $0.5 \mathrm{ml}$ starch solution $(1 \% \mathrm{v} / \mathrm{w}$ in acetate buffer of $\mathrm{pH} 4.8,0.1 \mathrm{M}$ ) and $0.1 \mathrm{ml}$ of appropriately diluted enzyme. The reaction was carried out at $30^{\circ} \mathrm{C}$ for $20 \mathrm{~min}$ and then arrested by boiling. Reducing sugars liberated were estimated by the DNS method using glucose as the reference standard. Enzyme activity was expressed in units $(\mathrm{U} / \mathrm{ml})$. One unit of enzyme activity is defined as $n$ moles of glucose liberated per min per ml under assay conditions.

\subsubsection{Estimation of ethanol concentration}

Samples (1g of fermented oilcake) were collected every $24 \mathrm{~h}$ up to $96 \mathrm{~h}$. The contents were dissolved in $2 \mathrm{ml}$ of water and centrifuged at $4^{\circ} \mathrm{C}$ for $10 \mathrm{~min}$ at
$10,000 \mathrm{rpm}$ to remove cells and residual oilcake and the supernatant was filtered using a country filter paper. The filtrate was diluted (1:10) with water and the amount of ethanol was estimated by back titration with sodium thiosulphate [18].

\section{Results and Discussion}

\subsection{Analysis of Carbohydrate content of Pongamia oilcake}

It is here for the first time, we report the total carbohydrate, starch and reducing sugar content of the Pongamia pinnata oilcake, the results of which are tabulated in Table 3.1.

Table 3.1.

\begin{tabular}{|c|l|c|}
\hline S.No. & Estimated Component & Percentage (\%) \\
\hline 1 & Total Carbohydrate & 23.00 \\
\hline 2 & Starch & 7.88 \\
\hline 3 & Reducing Sugars & 15.81 \\
\hline
\end{tabular}

\subsection{Glucoamylase activity of $A$. niger}

Figure 1 indicates the effect of inoculum concentration and incubation time on the glucoamylase activity of $A$. niger. Amylolytic activity of the culture increases concomitantly with the inoculum concentration yielding a maximum of $16.38 \mathrm{U} / \mathrm{ml}$ for $5 \%(\mathrm{~g} / \mathrm{g})$ of the culture at $96 \mathrm{~h}$. Irrespective of the inoculum level involved, the glucoamylase activity was found to increase simultaneously with time [19]. The results are in accordance with the fact that glucoamylase is an induced enzyme and its production increases with an increase in fungal biomass and incubation period [20].

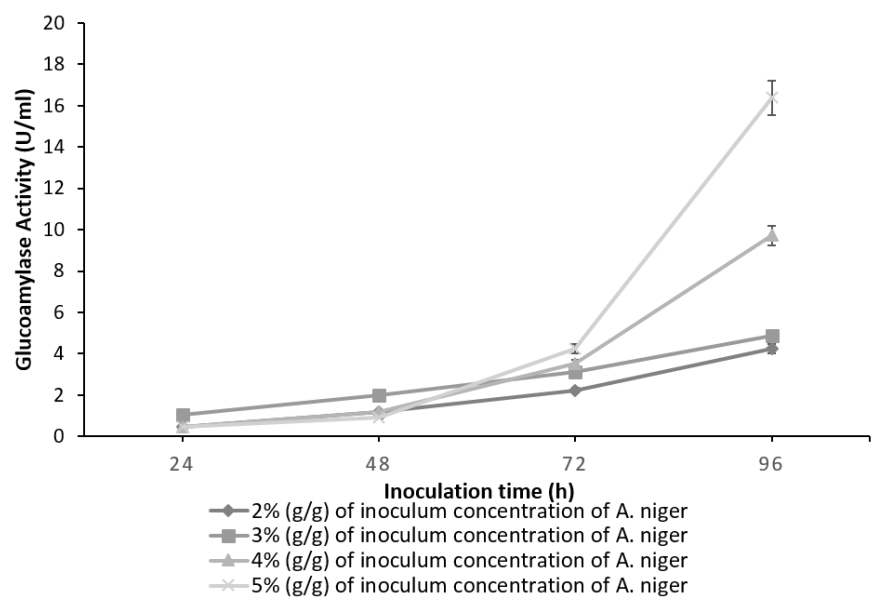

Figure 1. Glucoamylase activity of $A$. niger at varying inoculum concentration. 


\subsection{Ethanol Production}

\subsubsection{Effect of inoculum concentration}

It is evident from Figure 2 \& Figure 3 that for both of the combinations tried; the maximum ethanol concentration was obtained at 3\% inoculum level. As the inoculum concentration was increased to $4 \%(\mathrm{~g} / \mathrm{g})$ and $5 \%(\mathrm{~g} / \mathrm{g})$, concentration of the ethanol decreased. The results from our experiments are in accordance with the literature [19]. This is in contrast to the observed glucoamylase activity, maximum of which was obtained at $5 \%(\mathrm{~g} / \mathrm{g})$ inoculum of $A$. niger. The work by Abouzied et al., has rightly pointed that in a monoculture, more carbon is used for cell production leading to higher cell mass, which lead to the increased glucoamylase activity of $A$. niger in a monoculture whereas, in co-culture, most of the substrate carbon is utilized for ethanol production. Thus substrate is optimally utilized leading to maximum ethanol concentration at $3 \%(\mathrm{~g} / \mathrm{g})$ of co-culture. Any inoculum concentration greater than $3 \%(\mathrm{~g} / \mathrm{g})$ resulted in feedback inhibition, depleted nutrients and subsequently, low ethanol yield [22].

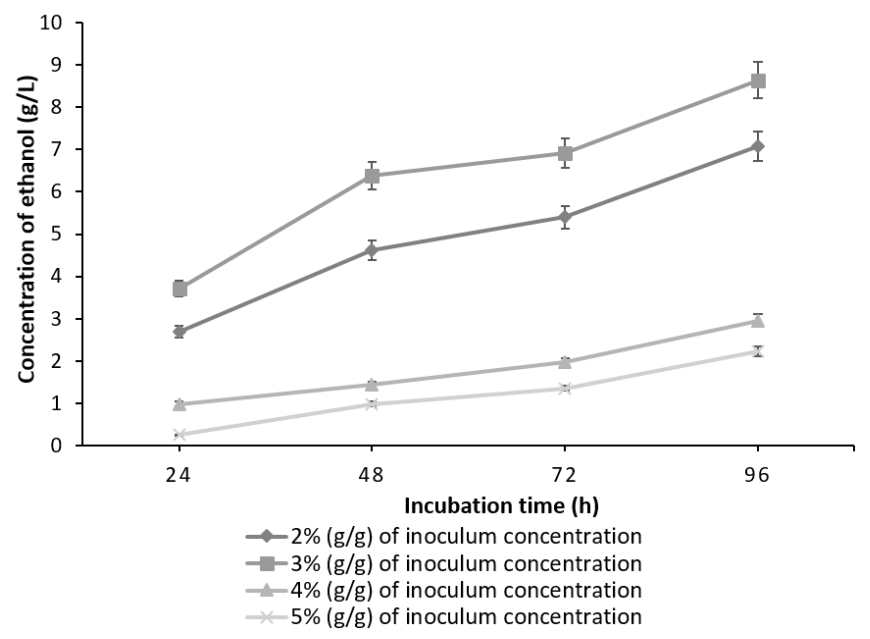

Figure 2. Ethanol production by co-culture of $S$. cerevisiae and $A$. niger at varying inoculum concentration.

\subsubsection{Effect of substrate concentration}

The batch fermented with S. cereviseae yielded a maximum ethanol concentration of $8.64 \mathrm{~g} / \mathrm{l}$ with $10 \mathrm{~g}$ of oilcake at $96 \mathrm{~h}$. Although, $10 \mathrm{~g}$ of the substrate yielded a maximum ethanol concentration at $96 \mathrm{~h}$, the profile of ethanol concentration using $5 \mathrm{~g}$ of the substrate is considered to be optimum. This is due to the fact that at $5 \mathrm{~g}$, the substrate was utilized very effectively producing an ethanol concentration of $6.96 \mathrm{~g} / \mathrm{l}$ at $48 \mathrm{~h}$ instead of 96h (Figure 4). On the contrary, with the combination of
K. marxianus and A. niger, ethanol production reached a peak of $7.41 \mathrm{~g} / \mathrm{l}$ at $96 \mathrm{~h}$ utilizing $15 \mathrm{~g}$ of the oilcake (Figure 5).

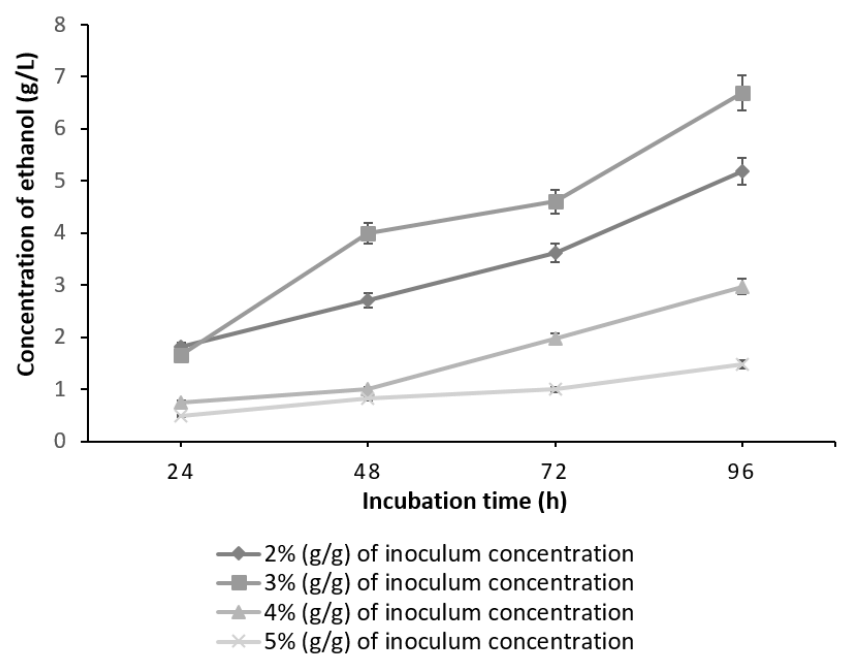

Figure 3. Ethanol production by co-culture of $K$. marxianus and $A$. niger at varying inoculum concentration.

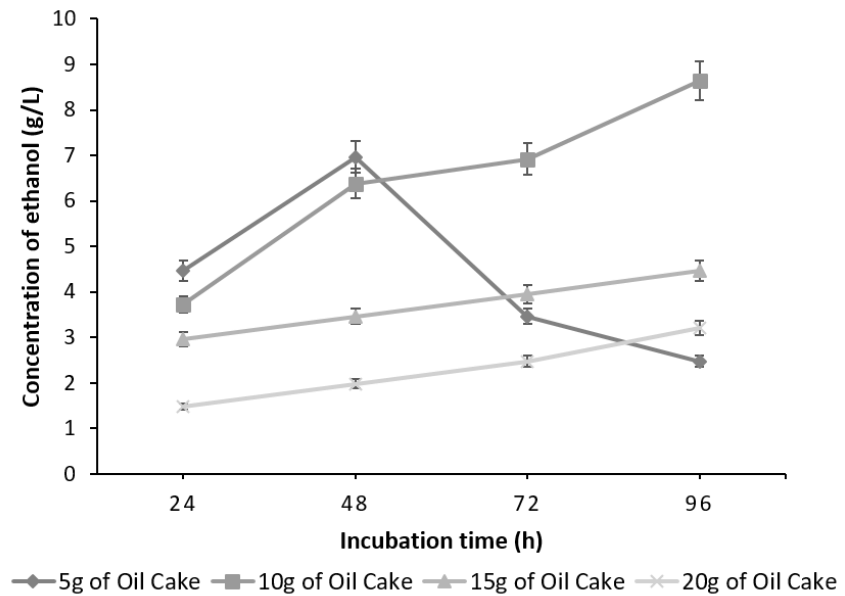

Figure 4. Ethanol production by co-culture of S. cerevisiae and A. niger at varying substrate concentration.

The decline in the ethanol concentration at higher substrate concentration is due to the increase in the osmotic pressure caused by the high sugar content, which tends to decrease the cell growth and ethanol fermentation [23], [24]. Any further increase in the substrate concentration did not improve ethanol production and has negative effects since the rate of saccharification and fermentation is directly proportional to substrate concentration up to the optimal level. This is because random collisions between the substrate and the active sites of the enzyme occur more frequently. Beyond the optimum concentration, all the active sites are saturated with the substrate and hence any further 
increase in substrate concentration has no effect on the rate of saccharification and fermentation.

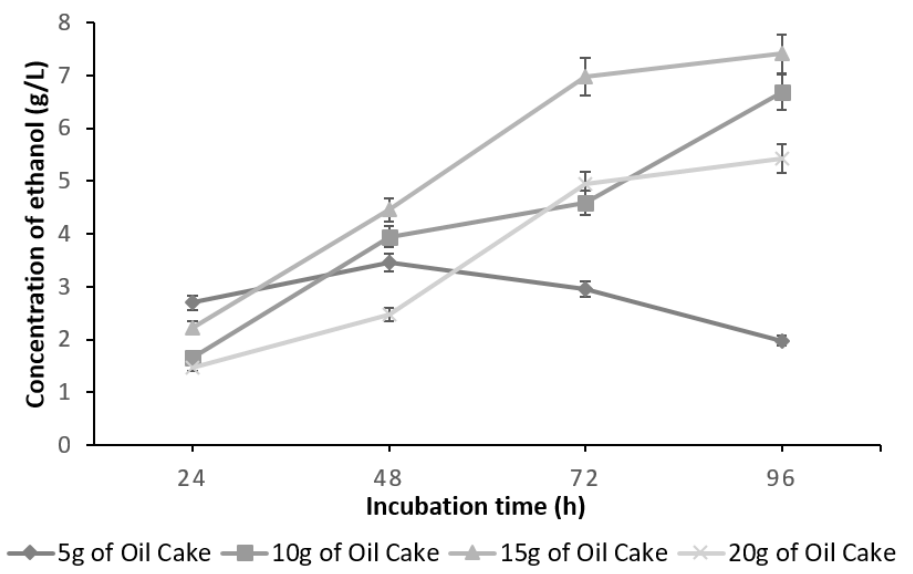

Figure 5. Ethanol production by co-culture of $K$. marxianus and $A$. niger at varying substrate concentration.

\subsubsection{Effect of incubation time}

The maximum production of ethanol was obtained at $96 \mathrm{~h}$ in both the batches of fermentation. The ethanol concentration profile tends to increase concomitantly with time as studied by earlier works [25]. Extending the fermentation time beyond $96 \mathrm{~h}$ would not be economical, as the goal of ethanol fermentation is to ferment in minimal time so that more batches can be processed in less time [26].

\subsubsection{Comparison of Fermentation by $S$. cerevisiae and $K$. marxianus}

The total carbohydrate, starch and reducing sugars were initially calculated for the defatted oilcake before SSF and were found to be 23\%, 7.88\% and 15 . $81 \%$. The same were calculated in the two batches of SSF which have yielded maximum ethanol concentration. The unutilized carbohydrates, starch and reducing sugars in co-culture of $3 \%(\mathrm{~g} / \mathrm{g})$ each of $S$. cerevisiae and $A$. niger utilizing $5 \mathrm{~g}$ of substrate after 48 $\mathrm{h}$ yielding $6.96 \mathrm{~g} / \mathrm{l}$ of ethanol was found to be $2 \%, 1.4 \%$ \& $0.8 \%$ whereas in a co-culture of $3 \%(\mathrm{~g} / \mathrm{g})$ each of $K$. marxianus and $A$. niger utilizing $15 \mathrm{~g}$ of substrate after $96 \mathrm{~h}$ yielding $7.41 \mathrm{~g} / \mathrm{l}$ of ethanol was found to be $3.33 \%$, $2.5 \%, 0.82 \%$ indicating that the starch was not the only carbohydrate which was utilized during the process of SSF. It can be concluded that the co-culture of $S$. cerevisiae and $A$. niger is more efficient than the mixed culture of $K$. marxianus and $A$. niger in terms of substrate utilization and the concentration of ethanol produced. This may be due to the fact that though the optimum temperature for the co-culture is $30^{\circ} \mathrm{C}$ [27], $\mathrm{K}$. marxianus is capable of producing higher concentrations of ethanol at higher temperatures [28], [29].

\section{Conclusion}

The ethanol production was studied using Pongamia oilcake containing a starch content of $7.88 \%$ $(\mathrm{w} / \mathrm{w})$. The results of this investigation clearly show that simultaneous saccharification and fermentation of Pongamia oilcake to ethanol by a mixture of starchdigesting fungus and a non-starch-digesting, sugarfermenting organisms such as $S$. cerevisiae and $K$. marxianus is feasible. Use of such a synergistic combination of organisms allows elimination of the enzymatic starch hydrolysis step as currently used in many commercial processes for ethanol production from starchy biomass, thereby significantly improving the economy of starch fermentation to ethanol. It equally revealed the fact that optimization of culture conditions could enhance ethanol production from oilcake using co-culture technique, thereby increasing the economy, in terms of percentage of starch fermentation to ethanol. Further scale-up studies are in progress for the production of ethanol from Pongamia oilcake by SSF.

\section{References}

[1] P. C. Badger, "Ethanol from cellulose: a general review," in Trends in new crops and new uses, Alexandria, ASHS Press, 2002.

[2] A. Eisentraut, "International Energy Agency (IEA).," 0102 2010. [Online]. Available: http://www.iea.org/papers/2010/second_genera tion_biofuels.pdf.

[3] B. Curtis, "2007 Year in Review U.S. Ethanol industry," 2008. [Online]. Available: http://www1.eere.energy.gov/bioenergy/pdfs/2 007ethanolreview.pdf.

[4] M. Galbe and G. Zacchi, "A review of the production of ethanol from softwood," Appl. Microbiol. Biotechnol., vol. 59, pp. 618-628, 2002.

[5] R. Chandra, V. K. Vijay and P. M. V. Subbarao, "Biogas production from de-oiled seed cakes of Jatropha and Pongamia.," Renewable Energy (Akshay Urja), vol. 3, no. 2, pp. 17-22, 2009.

[6] R. Chandra, K. Virendra, V. K. Vijay and P. M. V. Subbarao, "A study on biogas generation from non-edible oil seed cakes: Potential and Prospects 
in India," in The 2nd Joint International Conference on Sustainable Energy and Environment, 2006.

[7] D. Majumdar, "Unexploited botanical nitrification inhibitors prepared from Karanja plant," Natural Product Radiance, vol. 7, pp. 58-67, 2008.

[8] J. Santosh Kumar, K. Radhamani Anurudh, K. Singh and S. Varaprasad, "Germination and Seed storage behaviour in Pongamia pinnata L," Curr Sci., vol. 93, pp. 910-911, 2007.

[9] GreenerPro, "Pongamia pinnata," [Online]. Available:http://www.greenerpro.com/Pongamia .html.

[10] P. M. Guimarães, J. A. Teixeira and L. Domingues, "Fermentation of lactose to bio-ethanol by yeasts as part of integrated solutions for the valorisation of cheese whey," Biotechnol Adv., vol. 28, no. 3, pp. 375-384, 2010.

[11] K. Manikandan and T. Viruthagiri, "Kinetic and optimization studies on ethanol production from corn flour," Intl J Chem Biol Eng., vol. 3, pp. 65-69, 2012.

[12] S. A. Ado, G. B. Olukotun, J. B. Ameh and A. Yabaya, "Bioconversion of cassava starch to ethanol in a Simultaneous Saccharification and Fermentation process by co-cultures of $\mathrm{A}$. niger and $\mathrm{S}$. cerevisiae," Science World J., vol. 4, pp. 19-22, 2009.

[13] G. Verma, P. Nigam, D. Singh and K. Chaudhary, "Bioconversion of starch to ethanol in a singlestep process by coculture of amylolytic yeasts and S. cerevisiae 21," Bioresource Technol., vol. 72, pp. 261-266, 2000.

[14] H. T. M. Tran, B. Cheirsilp, B. Hodgson and K. Umsakul, "Potential use of Bacillus subtilis in a coculture with Clostridium butylicum for acetonebutanol-ethanol production from cassava starch," Biochem Eng J, vol. 48, pp. 260-267, 2010.

[15] H. Chen, Modern Solid State Fermentation: Theory and Practice, Springer Netherlands: Springer, 2013 edition.

[16] S. Sadasivam and A. Manickam, Biochemical Methods, 2nd ed. ed., India: New Age International Publishers, 1997.

[17] G. L. Miller, "Use of dinitrosalicylic acid reagent for determination of reducing sugar," Anal. Chem., vol. 31, pp. 426-428, 1957.

[18] A. M. Gupte and J. S. Nair, "ß Galactosidase production and ethanol fermentation from whey using Kluyveromyces marxianus NCIM 3551," J. Sci. Ind., vol. 69, pp. 855-859, 2010.

[19] S. Mishra and N. Behera, "Amylase activity of a starch degrading bacteria isolated from soil receiving kitchen wastes," Afr. J. Biotechnol., vol. 7, pp. 3326-3331, 2008.

[20] H. D. Zakpaa, E. E. Mak-Mensah and F. S. Johnson, "Production of bio-ethanol from corncobs using Aspergillus niger and Saccharomyces cerevisae in simultaneous saccharification and fermentation," Afr. J. Biotechnol., vol. 8, pp. 3018-3022, 2009.

[21] D. S. N. Benerji, C. Ayyanna, K. Rajini, B. SrinivasaRao, D. R. N. Banerjee, K. Swaroopa Rani and G. Rajkumar, "Studies on physico-chemical and nutritional parameters for the production of ethanol from Mahua Flower (Madhucaindica) using Saccharomyces cerevisiae - 3090 through submerged fermentation (smf)," J Microbial Biochem. Tech., vol. 2, pp. 46-50, 2010.

[22] M. M. Abouzied and C. A. Reddy, "Direct fermentation of potato starch to ethanol by cocultures of Aspergillus niger and Saccharomyces cerevisiae," Appl. Environ. Microbiol., vol. 52, pp. 1055-1059, 1986.

[23] M. P. Anupama, D. G. Mahesh and C. Ayyanna, "Optimization of fermentation medium for the production of ethanol from jaggery using BoxBehnken Design," Intl. J. Appl. Biol. Pharm Tech, vol. 1, pp. 34-45, 2010.

[24] T. D'Amore, C. J. Panchal and G. G. Stewart, "Intracellular ethanol accumulation in Saccharomyces cerevisiae during fermentation," Appl. Environ. Microbiol., vol. 54, pp. 110-114, 1988.

[25] S. Behera, R. C. Ray and R. C. Mohanty, "Comparative study of bioethanol production from Mahula flowers by immobilized cells of Saccharomyces cerevisiae and Zymomomnas mobilis," J. Sci. Ind. Res., vol. 69, pp. 472-475, 2010.

[26] B. Hoskins and M. Lyons, "Improving bioethanol yield: The use of solid-state fermentation products grown on DDGS," J. Inst. Brew., vol. 115, pp. 64-70, 2009.

[27] K. Manikandan and T. Viruthagiri, "Simultaneous Saccharification and Fermentation of wheat bran flour into ethanol using co-culture of amylotic Aspergillus niger and thermotolerant Kluyveromyces marxianus," Front. Chem. Eng. China, vol. 3, pp. 240-249, 2009. 
[28] P. J. Anderson, K. Mcneil and K. Watson, "Highefficiency carbohydrate fermentation to ethanol at temperatures above $40^{\circ} \mathrm{C}$ by Kluyveromyces marxianus var. marxianus isolated from sugar mills," Appl. Environ. Microbiol., vol. 51, pp. 13141320, 1986.

[29] G. G. Fonseca, E. Heinzle, C. Wittmann and A. K. Gombert, "The yeast Kluyveromyces marxianus and its biotechnological potential," Appl. Microbiol. Biotechnol., vol. 79, no. 3, pp. 339-354, 2008. 